\title{
The sibling as a factor of parental control over the use of gadgets by children
}

\author{
Nadezhda Sivrikova ${ }^{1 *}$,Elena Nemudraya $^{l}$, Natalya Gilyazeva ${ }^{1}$, Ekaterina Gnatyshina ${ }^{1}$, \\ Elena Moiseeva ${ }^{1}$ \\ ${ }^{1}$ South Ural State Humanitarian Pedagogical University, Chelyabinsk Lenin prospect 69, Russia
}

\begin{abstract}
The study aimed to examine the impact on parental strategies of regulating children's digital gadgets from having a second child in the family. Ninety-three mothers took part in the survey. Twenty women had two children, one woman - three children, the others women - on one child. Parents evaluated the frequency of use of digital devices by each child and then filled out several checklists. The mathematical processing of data is represented by the analysis of crosstabs (Cramer's V Test and Somer's D Test). The results of the study show that the use of digital devices is widespread among young children. At the same time, with the presence of senior siblings, the age of admission of the child to digital devices decreases. Thus, young children are exposed to digital technologies. Most parents seek to regulate the time and content children use. However, their rules were less stringent for the second child in the family. Parents should pay more attention to this.
\end{abstract}

\section{Introduction}

Scientists explain for various reasons interest in transforming childhood due to the widespread introduction of digital technologies. On the one hand, there is an intensive development of information technologies and their introduction into the daily practice of life. On the other hand, approaches in the education and upbringing of modern children are changing. Researchers note that digital technologies have significantly changed the habitat and development of children, contributed to increasing differences in generational mentality [1], led to new variations in childhood [2] and changing development norms[3].

There is a paradoxical situation in the world. Members of the digital migrant generation raise members of the digital natives' generation. Modern children are different from their parents. They communicate with friends, engage in creativity, play, get involved in activities end up differently than their parents in childhood. In such a situation, parents may experience pedagogical helplessness because they do not know how to behave correctly towards gadgets by children. The range of parental settings and rules ranges from a total ban on using even a TV set to allowing you to use a personal smartphone at any time during the day[4]. Scientific studies of media consumption factors are needed to create recommendations for the use of gadgets by children. The request from society encourages researchers all over the world.

* Corresponding author: bobronv@,cspu.ru 
They explore changes in media usage [5-7], risks to children health [8-10], factors influencing children's use of gadgets [11], the role of information technology in early childhood education[12,13], mediation of parents in use by children of digital devices $[4,14,15]$.

At the same time, most researches are devoted to the study of adolescents and much less attention is paid to infancy and early childhood. Initially, this inequality was justified because children in early childhood rarely encountered digital technology, becoming involved only in adolescence. Today, the situation has changed dramatically. Innovation in digital technology is emerging so quickly that scientists do not have time to study the consequences of their introduction [16]. A significant increase in access and use of mobile devices with Internet access by children of $0-8$ years old noted many researchers $[5,16,17]$. This is due to some objective reasons: The appearance of a touch screen that has simplified access to digital technologies; An example, on the part of parents and siblings who constantly use gadgets; The attractiveness of the digital device to the child; Development of the entertainment and educational content industry for young children. Researchers agree that there is a lack of research on digital use in early childhood [7]. In addition, most of the studies conducted have been carried out in developed countries in Europe and the United States. In Russia, there is an acute shortage of data on the peculiarities of digital technologies by children under the age of 8 . Therefore, we conducted a survey of moms, which was to identify the impact of the presence of siblings on the practice of using gadgets by children and the strategies used by parents in regulating this use

\section{Method}

\subsection{Study participants}

The obtained data allowed making groups out of 113 children. The first group included 91 children aged $0-8$ years old who do not have a senior sibling. The second one consisted of 22 children aged $0-8$ years old who have a senior sibling. In the groups, we compared different aspects: peculiarities of children ( $0-8$ years old) using digital devices, frequency of using them, and parents' mediation in children using the devices.

\subsection{Measures}

We surveyed parents who meant to report on their children aged 0 to 8 years old (babies, toddlers, preschoolers, and grade-schoolers).

Each question of the questionnaire had at least four options for answering the choice, as well as the opportunity to express their opinion in the form of the option "other." Answers to a question about children 's use of digital devices were transferred to the 6-ball Likert scale.

To assess the frequency of use of digital devices by children, parents were asked: "How often does your child use devices that provide Internet access (even if they are not connected to the network at the moment)?".

Participation in the research, which took place in two stages, was voluntary. During the first stage, we sent a reference to the online questionnaire to 200 mothers of children who lived in the Ural region (Russia). The questionnaire was created with Google Forms. The reference to the questionnaire was posted on the Russian social networking site (vk.com). The site was launched in 2006 to allow links with friends, private messaging, sharing media content, and later managing online communities. The mothers of children under study had a public profile in VK to access the questionnaire and answer the questions from June 10, 2019, to June 20, 2019. 
The second stage meant interviewing other mothers during their visit to the outpatients' department, where they filled out the same questionnaire. The mothers, who had not filled out the questionnaire online, could do it in writing from June 20, 2019, to June 28, 2019.

\subsection{Analysis plan}

We used Cramer's V Test, and Somer's D Test to mathematically process the results of the study. The software IBM SPSS Statistics 23 helped identify the number from 0 to 1 where the highest possible value could show perfect associations. IBM SPSS Statistics 23 displayed statistical significance via a p-value, which would prove the associations if it were less than 0.05 . Independent, moderate or perfect associations allowed concluding about the presence or absence of statistical differences of the obtained data.

\section{Findings}

\subsection{Dependence of children's use of digital devices on the availability of senior siblings}

We studied the use of digital devices by children. To do this, we asked parents whether their children use gadgets on their own, whether the child has a personal digital device and which one. We asked parents to indicate the approximate age when their children started using gadgets and the frequency of use of digital devices at the moment too.

The results of the comparison of media consumption in children are presented in Table 1.

Table 1. Dependence of the child's involvement in the use of digital devices on the presence of a sibling (\%).

\begin{tabular}{|c|c|c|c|c|}
\hline \multirow{2}{*}{ involvement indicators } & \multicolumn{2}{|c|}{$\begin{array}{l}\text { existence of the } \\
\text { senior sibling }\end{array}$} & \multirow{2}{*}{$\mathbf{V}$} & \multirow{2}{*}{$\mathbf{p}$} \\
\hline & $\begin{array}{c}\text { has no } \\
\mathbf{n}=91\end{array}$ & $\begin{array}{l}\text { has } \\
\mathrm{n}=\mathbf{2 2}\end{array}$ & & \\
\hline A child uses his digital gadgets & $40.7 \%$ & $27.3 \%$ & 0.109 & 0.246 \\
\hline $\begin{array}{l}\text { A child is just beginning to take an interest in digital } \\
\text { devices }\end{array}$ & $59.3 \%$ & $59.1 \%$ & 0.002 & 0.983 \\
\hline A child has his own digital device & $42.9 \%$ & $45.5 \%$ & 0.021 & 0.825 \\
\hline
\end{tabular}

It turned out that $38.1 \%$ of children who participated in the study use their digital devices, and $59.3 \%$ are just beginning to show interest in these technologies. $43.4 \%$ of children have their own digital devices.

The findings showed that $20.7 \%$ of children use gadgets every day and $29.7 \%$ several times a day. Do not use digital devices $1.8 \%$ of children who do not have such devices at home and $17.1 \%$ of children who have digital devices at home. It is rare to use gadgets 12.6 $\%$ of children (Table 2 ).

The study found no differences in the frequency of use of the gadget in children with senior siblings and children without senior siblings (Table 2). The findings also failed to 
confirm the hypothesis that there is a relationship between the degree of involvement of children in digital technology and the presence of senior siblings (Table 1).

Table 2. Frequency of use of digital devices by children (\%)

\begin{tabular}{|c|c|c|c|}
\hline \multirow{2}{*}{ frequency of use of gadgets } & \multicolumn{2}{|c|}{$\begin{array}{c}\text { existence of the } \\
\text { senior sibling }\end{array}$} & \multirow{2}{*}{ total } \\
\hline & $\begin{array}{c}\text { has no } \\
\mathrm{n}=91\end{array}$ & $\begin{array}{l}\text { has } \\
\mathrm{n}=\mathbf{2 2}\end{array}$ & \\
\hline Does not use, there are no digital devices at home. & $2.2 \%$ & $0 \%$ & $1.8 \%$ \\
\hline Does not use, the home has digital devices. & $20.9 \%$ & $0 \%$ & $17.1 \%$ \\
\hline Rarely used (several times a month). & $11 \%$ & $20 \%$ & $12.6 \%$ \\
\hline Used periodically (not more than once a week). & $2.2 \%$ & $10 \%$ & $3.6 \%$ \\
\hline Used frequently (several times a week). & $13.2 \%$ & $20 \%$ & $14.4 \%$ \\
\hline Used frequently (every day). & $18.7 \%$ & $30 \%$ & $20.7 \%$ \\
\hline Used frequently (several times a day). & $31.9 \%$ & $20 \%$ & $29.7 \%$ \\
\hline \multicolumn{4}{|c|}{ Somers'd Test Statistics } \\
\hline & Value & $\mathrm{T}^{\mathrm{b}}$ & $\mathrm{p}$ \\
\hline Symmetric & 0.024 & 0.39 & 0.697 \\
\hline Dependent variable usage rate & 0.045 & 0.39 & 0.697 \\
\hline
\end{tabular}

As can be seen from Table 3, the largest number of children start using gadgets on their own between the ages of 1 and 3 years $(37.2 \%)$ and after three years $(24.8 \%)$.

Table 3. Dependence of the age of involvement in the use of digital devices on the presence of sibling $(\%)$

\begin{tabular}{|l|c|c|c|c|}
\hline \multirow{2}{*}{ Age } & \multicolumn{2}{|c|}{ existence of the senior sibling } & \multirow{2}{*}{ V } & \multirow{2}{*}{ p } \\
\cline { 2 - 3 } & $\begin{array}{c}\text { has no } \\
\mathbf{n = 9 1}\end{array}$ & $\begin{array}{c}\text { has } \\
\mathbf{n = 2 2}\end{array}$ & & \\
\hline up to 6 months & $4.4 \%$ & $18.2 \%$ & 0.213 & 0.024 \\
\hline six months to 1 year & $8.8 \%$ & $9.1 \%$ & 0.004 & 0.965 \\
\hline about a year & $23.1 \%$ & $9.1 \%$ & 0.138 & 0.144 \\
\hline up to 3 years & $35.2 \%$ & $45.5 \%$ & 0.084 & 0.37 \\
\hline after 3 years & $26.4 \%$ & $18.2 \%$ & 0.075 & 0.424 \\
\hline
\end{tabular}

We found a link between the use of digital technologies by children of six months of age and the existence of an older sibling $(\mathrm{r}<0.05)$. In the group of children who have senior siblings, more who have started using digital devices under six months of age than in the group of children who do not have a senior sibling.

$43.4 \%$ of children ( $0-8$ age-old) who participated in the study have their digital device and at the age of 6-8 years, not even one. Most often in the study sample, children own phones/smartphones $(24.8 \%)$ and tablets $(21.2 \%)$. Only $6.2 \%$ of children ( $0-8$ age-old) have their computer (table 4).

The study results did not confirm the hypothesis of the relationship between the presence of the older sibling in the child and the type of gadget he owns $(p>0.05)$.

Data on the repertoire of use of gadgets by children are presented in Table 5.

Data on the repertoire of use of gadgets by children are presented in Table 5. According to the results of the research. Children most often play $(85.8 \%)$. There are also quite some children watching videos (43.4\%) and looking for information (34.5\%). Children under the 
age of 8 are little interested in digital photos/pictures $(3.5 \%)$ or online communication $(11.5 \%)$.

Table 4. Types of digital devices owned by children (\%)

\begin{tabular}{|l|c|c|c|c|}
\hline \multirow{2}{*}{$\begin{array}{l}\text { Type of the digital } \\
\text { device }\end{array}$} & \multicolumn{2}{|c|}{$\begin{array}{c}\text { existence of the } \\
\text { senior sibling }\end{array}$} & \multirow{2}{*}{$\mathbf{V}$} & \multirow{2}{*}{$\mathbf{p}$} \\
\cline { 2 - 5 } & $\begin{array}{c}\text { has } \\
\text { no } \\
\mathbf{n = 9 1}\end{array}$ & $\begin{array}{c}\text { has } \\
\mathbf{n = 2 2}\end{array}$ & & \\
\hline Phone/smartphone & $24.2 \%$ & $27.3 \%$ & 0.028 & 0.763 \\
\hline tablet & $17.6 \%$ & $36.4 \%$ & 0.182 & 0.053 \\
\hline computer & $7.7 \%$ & $0.0 \%$ & 0.126 & 0.179 \\
\hline other & $13.2 \%$ & $18.2 \%$ & 0.057 & 0.546 \\
\hline
\end{tabular}

The results of mathematical data processing did not confirm the hypothesis of the relationship between the presence of senior siblings and the type of activity of children on the Internet $(\mathrm{p}>0.05)$.

Table 5. Activities with gadgets in children (\%)

\begin{tabular}{|l|c|c|c|c|}
\hline \multirow{2}{*}{ activity types } & \multicolumn{2}{|c|}{$\begin{array}{c}\text { existence of the senior } \\
\text { sibling }\end{array}$} & V & p \\
\cline { 2 - 5 } & $\begin{array}{c}\text { has no } \\
\mathbf{n = 9 1}\end{array}$ & $\begin{array}{c}\text { has } \\
\mathbf{n = 2 2}\end{array}$ & & \\
\hline viewing videos & $45.1 \%$ & $36.4 \%$ & 0.069 & 0.46 \\
\hline gaming & $86.8 \%$ & $81.8 \%$ & 0.057 & 0.546 \\
\hline $\begin{array}{l}\text { information } \\
\text { search }\end{array}$ & $34.1 \%$ & $36.4 \%$ & 0.019 & 0.839 \\
\hline $\begin{array}{l}\text { viewing } \\
\text { photographs }\end{array}$ & $2.2 \%$ & $9.1 \%$ & 0.147 & 0.116 \\
\hline communication & $12.1 \%$ & $9.1 \%$ & 0.037 & 0.693 \\
\hline
\end{tabular}

\subsection{Parental mediation in children 's use of digital devices}

To explore the features of managing children 's consumption of digital devices by parents, we asked them if they limited access time for their children to digital technology; Whether the content used by their children was managed; In what situations they initiate using gadgets by the child.

It turned out that the vast majority of parents limit the time a child uses digital technologies (92.9\%). Only in $2.7 \%$ of cases, children used digital devices as much as they wanted. $30.1 \%$ of parents try to limit the time of use of the gadget, but it is difficult to specify exact time limits (Table 6).

$27.4 \%$ allow digital devices for a maximum of 30 minutes per day (Table 6). Parent's strategies differ significantly depending on the child's sibling. Younger children in the family limit access to gadgets $(r<0.05)$ less often and more often set a 3-hour limit on the use of digital devices $(\mathrm{r}<0.01)$.

$85.8 \%$ of parents follow the content their children access. Mothers choose the content for children $(45.1 \%)$. Some mothers $(20.4 \%)$ are watching what is considered safe and useful (Table 7). Only $12.4 \%$ of moms use special applications to restrict a child's access to Internet content. 
Table 6. Dependence of parental intervention in children 's use of gadgets on the presence of senior sibling $(\%)$

\begin{tabular}{|l|c|c|c|c|}
\hline \multirow{2}{*}{ Parents limit children 's access time to gadgets } & \multicolumn{2}{|c|}{$\begin{array}{c}\text { existence of the } \\
\text { senior sibling }\end{array}$} & \multirow{2}{*}{$\mathbf{V}$} & \multirow{2}{*}{$\mathbf{p}$} \\
\cline { 2 - 3 } & $\begin{array}{c}\text { has no } \\
\mathbf{n = 9 1}\end{array}$ & $\begin{array}{c}\mathbf{h a s} \\
\mathbf{n = 2 2}\end{array}$ & & \\
\hline I limit a child's access time to gadgets. & $95.6 \%$ & $81.8 \%$ & 0.213 & 0.024 \\
\hline $\begin{array}{l}\text { The child uses digital devices as much as they } \\
\text { want. }\end{array}$ & $2.2 \%$ & $4.5 \%$ & 0.58 & 0.539 \\
\hline $\begin{array}{l}\text { I try to limit the time of the child at the computer, } \\
\text { but I find it difficult to specify the exact time limits. }\end{array}$ & $35.2 \%$ & $9.1 \%$ & 0.225 & 0.17 \\
\hline $\begin{array}{l}\text { I allow digital devices no more than 3 hours per } \\
\text { day. }\end{array}$ & $16.5 \%$ & $45.5 \%$ & 0.276 & 0.003 \\
\hline $\begin{array}{l}\text { I allow digital devices no more than 30 minutes per } \\
\text { day. }\end{array}$ & $27.5 \%$ & $27.3 \%$ & 0.002 & 0.985 \\
\hline $\begin{array}{l}\text { I completely prohibit children from using digital } \\
\text { devices. }\end{array}$ & $16.5 \%$ & $0.0 \%$ & 0.192 & 0.041 \\
\hline
\end{tabular}

There are differences in attitudes towards children at the content control point $(\mathrm{r}<0.05)$. It turned out that parents are less likely to follow the content that junior sibling uses.

Table 7. Content restriction strategies used by parents (\%)

\begin{tabular}{|c|c|c|c|c|}
\hline \multirow{2}{*}{ Restriction of content } & \multicolumn{2}{|c|}{$\begin{array}{c}\text { existence of the senior } \\
\text { sibling }\end{array}$} & \multirow{2}{*}{$\mathbf{V}$} & \multirow[b]{2}{*}{ p } \\
\hline & $\begin{array}{c}\text { has no } \\
\mathbf{n}=91\end{array}$ & $\begin{array}{c}\text { has } \\
\mathbf{n}=\mathbf{2 2}\end{array}$ & & \\
\hline I follow the content my child uses & $89 \%$ & $72.7 \%$ & 0.185 & 0.049 \\
\hline $\begin{array}{l}\text { I use special applications to restrict children } \\
\text { 's access to the Internet }\end{array}$ & $13.2 \%$ & $9.1 \%$ & 0.049 & 0.601 \\
\hline I choose content for the child & $47.3 \%$ & $36.4 \%$ & 0.087 & 0.357 \\
\hline $\begin{array}{l}\text { I allow watching (play) only what I } \\
\text { consider safe/useful }\end{array}$ & $23.1 \%$ & $9.1 \%$ & 0.138 & 0.144 \\
\hline
\end{tabular}

Of interest are situations in which mothers themselves invite children to use a tablet (Table 8). Mothers choose such a strategy in a situation where they are engaged in their affairs most often $(52.2 \%) .33 .6 \%$ of parents give children a gadget during the trip. Only $23.9 \%$ of moms do not offer gadgets to children under any conditions.

Table 8. Situations in which parents initiate the use of the gadget by a child (\%)

\begin{tabular}{|l|c|c|c|c|}
\hline \multirow{2}{*}{ Situations } & \multicolumn{2}{|c|}{$\begin{array}{c}\text { existence of the } \\
\text { senior sibling }\end{array}$} & \multirow{2}{*}{$\mathbf{V}$} & \multirow{2}{*}{$\mathbf{p}$} \\
\cline { 2 - 4 } & $\begin{array}{c}\text { has no } \\
\mathbf{n = 9 1}\end{array}$ & $\begin{array}{c}\mathbf{h a s} \\
\mathbf{n = 2 2}\end{array}$ & & \\
\hline $\begin{array}{l}\text { When it is necessary to occupy the child that he did } \\
\text { not prevent to make an important issue }\end{array}$ & $51.6 \%$ & $54.5 \%$ & 0.023 & 0.807 \\
\hline during a trip & $35.2 \%$ & $27.3 \%$ & 0.066 & 0.482 \\
\hline in the queue (for example, in the polyclinic) & $29.7 \%$ & $27.3 \%$ & 0.021 & 0.824 \\
\hline before going to bed & $6.6 \%$ & $9.1 \%$ & 0.039 & 0.682 \\
\hline during feeding & $2.2 \%$ & $0 \%$ & 0.066 & 0.483 \\
\hline I do not offer digital devices in any situation & $23.1 \%$ & $27.3 \%$ & 0.039 & 0.679 \\
\hline
\end{tabular}


Thus, the study obtained data indicating that parent's strategies for children's use of gadgets depend on the child having a senior sibling.

\section{Discussion and conclusion}

The use of digital devices in our study (38.1\%) coincides with data from American studies (33\%) [18] and lower than according to French researchers (58\%) [7]. Researchers believe that the difference in data can be explained by some reasons. For example, divergence inhabits methodological differences [19].

According to parents, children around the world are indeed exposed to digital technologies from early childhood. This confirms the need for research to study the consequences of the use of digital technologies by children. However, we believe that both ours and the results of other research suggest that measuring these effects under natural conditions will be problematic. It should be noted that $35.1 \%$ of children from our study use gadgets less than once a week. It is unlikely that this will result in a significant shift or competition with other activities (such as subject play, parent interaction). As a result, the real effects of using digital technologies should be so small and volatile that they can only be detected on extremely large samples.

Our study studied the types of content that children consume. We found that common activities for children are gaming and watching videos. Some other researchers produced similar conclusions $[5,7,20,21]$. Watching videos cannot be classified as an interactive activity. Researchers believe that it is the interactivity that attracts children to gadgets. However, children may be using interactive features when watching videos, such as choosing videos themselves. In addition, we did not wonder what kind of video content children viewed. We believe that future questionnaires interested in the effects of watching videos by children should take into account the content of video materials presented on the touch screen. Researchers need to specify the degree of autonomy of the child selecting content to view.

It should be noted that viewing pictures/photos by popularity among Russian children was in the last positions (3.5\%). Study participants differ from children from France in this parameter. For children from France, photo viewing was the most common activity when using gadgets (78\%) [7]. Perhaps this is because young children like to look at photos with parents, and such practice is not common in Russian families. Another explanation may be that without an intermediary, this activity does not attract young children. And the question in our study was the child's independent use of a digital device.

The data we have obtained support the idea that parents rate digital technologies positively, but at the same time, consider them difficult to control and regulate. The first is evidenced by the fact that most children have access to digital devices $(43.4 \%$ have their gadget). The second is indicated by the fact that parents limit the time of access of the child to gadgets $(92.9 \%)$.

On the one hand, digital technologies help parents solve problems related to the management of the child's behaviour, promote his/her education and development. On the other hand, the use of digital media by children appears as problematic. Parents strive to control this area of children's lives. Some of them who do not consider it necessary to monitor how their children use the Internet. Other parents prefer to follow the content their child uses. Moreover, like Turkish parents [6], only one in 10 Russian parents resort to special programs to solve this problem.

In general, the study results indicate that there is a need for science-based guidelines for the use of digital technologies for parents of the child in early childhood, as well as for a plan for the use of digital devices by children. 
Our hypothesis has not been confirmed. The presence of senior siblings does not lead to earlier involvement of the child in digital technologies. The presence of siblings does not affect the frequency and time of consumption of digital devices by children ( $0-8$ age-old). The differences found in the study indicate that the availability of senior siblings depends on the likelihood of a child joining digital devices up to the age of 6 months and the setting of parents to limit the use of gadgets by children. We established that the presence of senior siblings leads to the easing of parental requirements for the use of digital devices by the youngest sibling.

The study results can be explained by the fact that in the absence of problems related to the use of a digital device in an older child, parents tend to ease their requirements for the youngest child. Perhaps the perception of the youngest child in the family as needing a special, soft approach plays a role, as he is a baby. However, these assumptions need further empirical confirmation.

Finally, the limitations of this study should be noted. The most significant limitation of our data relates to the sample. Sampling characteristics do not allow us to abstract the conclusions (number of participants, difference in the volume of groups). However, in most cases, the data we obtained were similar to other researchers from Europe and the United States.

The second limitation is since parents were the source of information. Their reports are subjective and may distort the results of the study. It is currently unknown to what extent such reports reflect reality. Because parents may have beliefs about what should be reported and whatnot.

\section{References}

1. V. Pishchik, Eur. Proc. Soc. Behav. Sci. XLIII, 461 (2018).

2. K. N. Polivanova, J. Mod. Foreign Psychol. Зарубежная Психология 5, 5 (2016).

3. G. U. Soldatova, Soc. Psychol. Soc. Психология и Общество 9, 71 (2018).

4. Y. Hwang, I. Choi, J. Y. Yum, and S. H. Jeong, Cyberpsychology, Behav. Soc. Netw. 20, 362 (2017).

5. Y. R. Chassiakos, J. Radesky, D. Christakis, M. A. Moreno, C. Cross, D. Hill, N. Ameenuddin, J. Hutchinson, R. Boyd, R. Mendelson, J. Smith, and W. S. Swanson, Pediatrics 138, (2016).

6. M. Dinleyici, K. B. Carman, E. Ozturk, and F. Sahin-Dagli, Interact. J. Med. Res. 5, e18 (2016).

7. A. Cristia and A. Seidl, PLoS One 10, e0128338 (2015).

8. T. Hinkley, V. Verbestel, W. Ahrens, L. Lissner, D. Molnar, L. A. Moreno, I. Pigeot, H. Pohlabeln, L. A. Reisch, P. Russo, T. Veidebaum, M. Tornaritis, G. Williams, S. De

Henauw, and I. De Bourdeaudhuij, JAMA Pediatr. 168, 485 (2014).

9. A. I. Nathanson, F. Aladé, M. L. Sharp, E. E. Rasmussen, and K. Christy, Dev. Psychol. 50, 1497 (2014).

10. J. H. Moon, S. Y. Cho, S. M. Lim, J. H. Roh, M. S. Koh, Y. J. Kim, and E. Nam, Acta Paediatr. Int. J. Paediatr. 108, 903 (2019).

11. C. K. Blackwell, A. R. Lauricella, and E. Wartella, Comput. Educ. 77, 82 (2014).

12. Ukwueze Frederick and Ajala Esther, Comput. Educ. Res. J. 1, 127 (2014).

13. A. de O. Hansen and A. de O. Hansen, Cad. Educ. Tecnol. E Soc. 10, 207 (2017).

14. D. L. Linebarger, R. Barr, M. A. Lapierre, and J. T. Piotrowski, J. Dev. Behav. Pediatr. 
35, 367 (2014).

15. J. S. Radesky, E. Peacock-Chambers, B. Zuckerman, and M. Silverstein, JAMA Pediatr. 170, 397 (2016).

16. J. L. Miller, K. A. Paciga, S. Danby, L. Beaudoin-Ryan, and T. Kaldor, Cyberpsychology 11, (2017).

17. J. Zabatiero, L. Straker, A. Mantilla, S. Edwards, and S. Danby, Australas. J. Early Child. 43, 14 (2018).

18. H. K. Kabali, M. M. Irigoyen, R. Nunez-Davis, J. G. Budacki, S. H. Mohanty, K. P. Leister, and R. L. Bonner, Pediatrics 136, 1044 (2015).

19. N. V. Sivrikova, T. G. Ptashko, A. E. Perebeynos, E. G. Chernikova, N. V. Gilyazeva, and V. S. Vasilyeva, Educ. Inf. Technol. 25, 3957 (2020).

20. A. O. Kılıç, E. Sari, H. Yucel, M. M. Oğuz, E. Polat, E. A. Acoglu, and S. Senel, Eur. J. Pediatr. 178, 221 (2018).

21. O. V. Krukhmaleva and E. V. Krukhmalev, Krukhmaleva 2, 47 (2017). 